\title{
The Psychosocial Impact of Modifying Face and Body Photographs in Social Media
}

\author{
Alexandra Valéria Sándor
}

Eötvös Loránd University, Faculty of Social Sciences, Doctoral School of Sociology, Hungary

\section{ARTICLE INFO}

Keywords:
Body Image
Image Alteration
Mental Health
Social Psychology
Sociology

\begin{abstract}
Social media usage has become widespread in the past decade, and studying its far-reaching impacts requires an interdisciplinary approach. This pilot study takes the first step in discovering the psychosocial impact of specific media content, modified face and body photographs, and the act of modifying in this context with a mixed-method assessment. The analysis is based on structured interviews with ten social media users with various demographic traits (such as gender, age, or education) who were presented eight pairs of "before-and-after modification" photographs and completed the Beck Depression Inventory (BDI) to assess a possible relationship between modified face and body photographs in social media and depression. All the participants encountered such face and body photographs that they considered "modified". The definition of modification was "retouching, editing, using filters or any kind of digital altering mechanism". Seventy per cent of users admitted that they took the opportunity to modify photographs of their face and body. The average Beck score of the image modifiers was 7.14, while non-modifiers' was 2.33 . Thirty per cent of the interviewees probably had mild depression or were in a mildly depressive state during the data collection based on their Beck scores; all were image modifiers exposed to modified pictures. Besides the fully structured interviews with social media users, half-structured interviews were also recorded with four experts - a social psychologist, a clinical psychologist, a plastic surgeon, and a professional photographer - to gain a deeper understanding of this complex topic and contribute to further, more extensive research on this area.
\end{abstract}

\section{Introduction}

Social media social media has its own logic, which includes special norms, strategies and mechanisms (van Dijck \& Poell, 2013). On social media, one can see virtual selfrepresentations that are influenced by 'real-life' individual and societal changes (Hogan \& Quan-Haase, 2010 and Sándor, 2020). Research examining the various patterns, reasons, and effects of social media usage is ubiquitous. Certain things are now universally recognised. For example, friends' pictures on social media have the biggest impact on women's body image (Hogue \& Mills, 2019). Facebook usage was also associated with body image concerns in young women (Fardouly \& Vartanian, 2015). However, ethical questions about photo modification in the media arose long before social media became part of everyday life (Wheeler \& Gleason, 2010). The penetration of social media usage is so vast that the largest platform, Facebook, had 2.45 billion active monthly users as of the third quarter of 2019 (Clement, 2019). It is also known that users' mental states can be detected by traces left behind on Facebook

\footnotetext{
* Corresponding Author E-Mail Address: sandor.alexandra.valeria@gmail.com
} 
(Csepeli \& Nagyfi, 2014). In the literature, frequent social media use has been associated with a higher risk of depression (Lin et al. 2016). The examination of social media's far-reaching impact requires an interdisciplinary approach (Kende et al., 2015). The goal of this pilot study is to initiate a discussion on the psychosocial impact of modified face and body photographs, and the modification itself in this specific environment with a mixed-method analysis and to examine whether this research topic is suitable as part of a $\mathrm{PhD}$ dissertation.

\section{Methods}

Assessing the psychosocial impact of modifying face and body photographs in social media is a rather complex task which can only be examined using a mixed method. Individual social media usage patterns, exposure and attitude to modified pictures, and the possible habit of modifying own pictures were assessed with a classic qualitative method: structured one-on-one interviews during in-person meetings with ten Hungarian social media users with various demographic traits, e.g. gender, age, or education. During the interviews, which took place at Eötvös Loránd University, Faculty of Social Sciences, the participants were presented with eight pairs of "before-and-after modification" photographs with 4 pairs of face plus 4 pairs of face and body images. They subsequently completed the Beck Depression Inventory (BDI), which is a 21-question multiple-choice self-report inventory, one of the most widely used psychometric tests to detect overall mental health status and the severity of a possible depression. Participants were selected with snowball sampling. Besides the fully structured interviews with social media users, half-structured interviews were also recorded with four Hungarian experts: Dr György Csepeli, social psychologist, professor emeritus of Eötvös Loránd University, Faculty of Social Sciences; Orsolya Pócsi, clinical psychologist, lecturer of University of Miskolc, Faculty of Arts; Dr Gergely Pataki, chief plastic surgeon, Premium Plastic Surgery, Budapest; and Miklós Bemer, professional photographer of model agencies and licensed beauty pageants. Each interview was individually recorded between November 17 and December 9, 2019.

\section{Results and Discussion}

The interviewed sample of the ten social media users consisted of four men and six women with an average age of 41 years and a median age of 36.5 years. The youngest participant was 15 years old, while the oldest was 70. Regarding their level of education, $40 \%$ had a university (MA/MSc) degree, 30\% had a college (BA/BSc) degree, 20\% completed secondary school, and the youngest participant still attended secondary school. According to the BDI, 30\% probably had mild depression or were in a mildly depressive state during the data collection and had 10-18 points, while $70 \%$ could be classified as depression-free or minimally depressive with less than 10 points based on their answers. The average Beck score was 5.7 points, and the median score was 4 . All participants used social media: 100\% consumed images on Facebook, $80 \%$ on Instagram, 30\% on LinkedIn, $20 \%$ on Pinterest, and $10 \%$ on Snapchat. The least active user spent " 3 minutes a year" browsing social media, while the most active was "online in every waking minute", which meant 16 hours per day. The average daily time on social media was 172 minutes, with a median of 69 minutes.

All of the participants encountered face and body photographs that they considered "modified". (The author's definition of modification was "retouching, editing, using filters or any kind of digital altering mechanism".) On social media, 80\% saw such images on Facebook, $70 \%$ on Instagram, $20 \%$ on LinkedIn, and $10 \%$ on Pinterest and Snapchat. Half of the interviewed users saw modified face and body photographs "multiple times a day", 30\% "once a day", 10\% "multiple times a week", and $10 \%$ "only a few times". Nine of the ten social media users encountered modified face and body photographs of their acquaintances - the only one who did not, spent just "3 minutes a year" on social media. During the in-person interviews, $70 \%$ of 
the users admitted that they took the opportunity to modify photographs of their face and body. It happened "multiple times a week" to $10 \%$, "few times a month" to $10 \%$, "few times a year" to $30 \%$, and "few times at all" to $20 \%$. Most of them published the modified photo on social media: $40 \%$ on Facebook, 30\% on Instagram, $10 \%$ on LinkedIn, and 10\% on Snapchat. To the question "Did you manage to achieve the desired goal with posting a modified image of you?", all of them answered "yes". The average Beck score of the image modifiers was 7.14, while non-modifiers was 2.33 . The $30 \%$ of the interviewees who probably had mild depression or were in a mildly depressive state during the time of data collection based on their Beck scores were all image modifiers exposed to modified pictures.

What motivates people to modify photographs of their faces and bodies?

Different cultures have different ritual reasons for changing their bodies. Modern body modification is related to strengthening a person's market value and increasing their marketability. Everyone wants to be attractive and enhance their appeal. Image modification is like a cheap and immediately available alternative to plastic surgery. The basic idea is that you like yourself better if others like you: an interesting fusion of narcissism (to please yourself) and making yourself attractive to others (to please them). Life became a desperate race against time that destroys the face and the body. Until we find the genetic antidote to ageing, technologies to enhance this type of marketability need to be available. This is the consequence of externally directed consumer capitalism, explained social psychologist Dr Csepeli in the interview.

"She is a product", said one of the social media users seeing the same portrait of a well-known American celebrity before-and-after modification. "She's a slave of this image. Ageism is strong, you can't get old, it's all about looks. If you don't meet the standards, you're not good enough, you'll be worthless. She can't be like an average person. They are selling this illusion". "I'd definitely not buy her album if she put the before photo on the cover", admitted another interviewee. "The left one could be next door Mary, and the right one is Beyoncé", as the third participant grasped the result of the modification.

"You need to follow the trend to be competitive, or you will be left out completely. People are searching for values everywhere, assuming things that are not true", warns clinical psychologist Pócsi. She recalled that humans are lied to as many as 200 times a day in general, according to the 1977 book of social psychologist Jerald Jellison of the University of Southern California. "In smaller or bigger things, the photographic world also lies. You can't believe what you see. How can you orientate yourself under these circumstances? There is great uncertainty, the reference point is unstable", summarised Pócsi. "Sometimes I wonder why people modify a certain part of their face or body that they do. What is the goal? I do not know", shared one of the social media users. "Why on earth would you make a plus-size model look skinnier? The whole point of being plus-size is not to be skinny, isn't it?" asked the same interviewee seeing a retouched photo of a plus-size model next to the original one. "Everyone has a built-in sense of beauty, with the golden ratio and everything, something about the proportions we find beautiful. Here they tried to approach it. If we are already showing something to the world, devoting efforts to it, then it should be perfect, because more people will buy the newspaper or the advertised product. It's a general phenomenon, aiming for more profit", pointed out one of our participants.

People compare themselves to the ideal images that are created by advertising professionals who identified those ideal images that seem most attractive to a particular group, that they can sell a product with, stated plastic surgeon Dr Pataki. Hair, skin colour, eye colour, eyebrow shape, smile, fullness. Everything counts. Unblemished skin, facial symmetry are a must on these pictures we are surrounded with. There is no time to think about whether you identify with them or not: it works as an elementary reflex. In a tenth of a second, you are trying to resemble. You want to be young and perfect. You want to gain a selective advantage which is 
an evolutionary instinct like when peacocks trick their potential mate with their pen-feathers, added Dr Pataki.

"Everyone has their own face, and what they want to show is a little different for everyone. You feel the need to improve your image for the outside world to be accepted or to prevail. This is semi-legitimate, as we can see countless times that those are favoured who do it for some interest", described a social media user during the interview. "This is like a typical beforeafter commercial", said another while looking at the original and modified portraits of a young woman. "The first is completely spontaneous, the second is completely artificial. The first is more human, the second is more like a robot", illustrated another social media user.

"Human face is the play of lights and shadows, and people are susceptible to the harmony of this game. You find it beautiful if the contours follow a line, are continuous and have a nice curve", clarified Dr Pataki. "Modifying the lights is the first step of retouching a photo", stated professional photographer Miklós Bemer. "Digital image modification is like adding half a dimension to a two-dimensional picture to make it more three-dimension like, more alive. I manipulate things to show the best side of the person being photographed. I make irrelevant defects disappear. I only modify things that are irrelevant when looking at a person, starting from the most obvious defects to the smaller ones: I don't add and I don't take away anything essential", explained Bemer.

To the question if the widening availability of digital image modifying tools and applications make any difference, the photographer said, "Unfortunately, not only professional and reasonable points of view exist. We see distorted, unrealistic images in social media. Who doesn't understand this, can lose themselves quickly. This unrealistic distortion destroys the image of oneself with drawing attention to their supposed defects, and intensifying the desire to look like the person they idealise". Among the interviewed social media users, one person said, "Yes, I publish modified pictures of myself to Facebook where the lights are adjusted, my face and hair are made more perfect, and my skin unblemished", Others modified the "lights", "colours", "background", and "disturbing details", e.g. blemishes, darkness, distortions, on photographs of their face and body. One of them simply said, "I correct my body shape". The most frequent tools were Instagram filters (among all Instagram users), but they mentioned FaceApp and Photoshop as well. There was a unanimous understanding during each user interview that the modification below "is OK" because "removing blemishes is acceptable". However, two women participants noted that "I hope that he didn't upload the modified picture to a dating site" because it might result in "disappointment".

"Modifying your face and body photographs is sheer self-deception", Dr Csepeli believes. The social psychologist adds, "People are very self-deceived, tend to look at themselves in an idealised way, and accept the idealised image as their own image. Retouching is the anteroom of cosmetic interventions. Everyone likes to look better, more beautiful, more perfect. In social media, there is immediate feedback which is appealing". Plastic surgeon Dr Pataki talked about the same phenomenon: "Patients who brought the image of others to show the result they wanted had to be rejected by international plastic surgery standards. Today, however, professional guidelines have changed. Every third patient between 18 and 30 comes with images seen on the Internet: most are from Facebook or Instagram, which depict people in a distorted, anatomically impossible way". One of the interviewees noted that "my Facebook connections try to resemble the manipulated pictures seen in social media and newspapers on their published photos". Another participant said their social media connections tend to modify "mainly the structure of their face, but there are also some who do not look exactly like their picture: sometimes I do not even know who is in the picture because she is a bit more corpulent in real life".

Clinical psychologist Pócsi warns that "Social media doesn't work as a real mirror, it's not about real images, not about real connections. High-school-age children are at a higher risk because 
they are susceptible to the world of modified images. Even my own child of this age asks me not to post anything without editing it before!"

\section{Conclusion}

Notwithstanding the small sample size in this pilot study, the results speak to the long-running debate about the psychosocial impact of modifying face and body photographs in social media. The results produced from the mixed-method analysis support the hypothesis that social media users are exposed to modified or manipulated face and body photographs through their connections, and they might tend to modify their pictures as well. The findings suggest that modifying face and body photographs will likely persist in social media since there is a demand which originates partly in human nature, partly in the consumer society. Based on the Beck scores of the participants, there might be a relation between the inclination to modify pictures of self and mental health. Without a concerted effort to recognise the broad and long-term consequences of such image modifications, this phenomenon might contribute to the spreading of mental and physical health issues as well. Hopefully, these findings demonstrate the need to extend research examining the psychosocial impact of modifying face and body photographs in social media.

\section{Acknowledgements}

The author would like to thank Eötvös Loránd University, Faculty of Social Sciences, Doctoral School of Sociology for the intellectual background, under the supervision of Dr György Csepeli, head of the Interdisciplinary Social Research doctoral programme.

Special thanks to the experts for the interviews: Dr György Csepeli, social psychologist, professor emeritus at Eötvös Loránd University, Faculty of Social Sciences; Orsolya Pócsi, clinical psychologist, lecturer at University of Miskolc, Faculty of Arts; Dr Gergely Pataki, chief plastic surgeon, Premium Plastic Surgery, Budapest; and Miklós Bemer, professional photographer for model agencies and licensed beauty pageants.

\section{References}

Hogue, J. V. and Mills, J. S. (2019). "The effects of active social media engagement with peers on body image in young women," Body Image, vol. 28, pp. 1-5.

Fardouly, J. and Vartanian, L. R. (2015). "Negative comparisons about one's appearance mediate the relationship between Facebook usage and body image concerns," Body Image, vol. 12, pp. 82-88.

Wheeler, T. and Gleason, T. (1995). "Photography or photofiction: An ethical protocol for the digital age," Visual Communication Quarterly, vol. 2, pp. 8-12.

Clement, J. (November 2019). "Number of monthly active Facebook users worldwide as of 3rd quarter 2019 (in millions)." Available: https://www.statista.com/statistics/264810/numberof-monthly-active-facebook-users-worldwide/

Csepeli, G. and Nagyfi, R. (2000). "Facebook diagnostics: Detection of mental health problems based on online traces," European Journal of Mental Health, vol. 9(2), pp. 220-230.

Hogan, B., \& Quan-Haase, A. (2010). "Persistence and change in social media," Bulletin of Science, Technology \& Society, vol. 30(5), pp. 309-315.

Kende, A., Ujhelyi, A., Joinson, A. and Greitemeyer, T. (2015). "Putting the social (psychology) into social media," European Journal of Social Psychology, vol. 45, pp. 277278. 
Lin, L. Y., Sidani, J. E., Shensa, A., and Radovic, A. et al. (2016). "Association between social media use and depression among U.S. young adults," Depression and Anxiety, vol. 33(4), pp. 323-331.

Sándor, A. V. (2020). "Self-Representation in Social Media During the COVID-19 Pandemic Lockdown," European Journal of Social Sciences, vol. 3(2): pp. 113-126.

van Dijck, J. and Poell, T. (2013). "Understanding social media logic," Media and Communication, vol. 1(1), pp. 2-14. 